\title{
Breathing pattern, thoracoabdominal motion and muscular activity during three breathing exercises
}

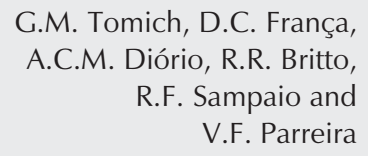

Departamento de Fisioterapia, Escola de Educação Física, Fisioterapia e Terapia Ocupacional, Universidade Federal de Minas Gerais, Belo Horizonte, MG, Brasil

\section{Correspondence}

V.F. Parreira

Departamento de Fisioterapia

Escola de Educação Física,

Fisioterapia e Terapia Ocupacional

UFMG

Av. Antônio Carlos, 6627

31270-091 Belo Horizonte, MC

Brasil

Fax: +55-31-3499-4783

E-mail: parreira@ufmg.bror

veronica.parreira@pesquisador.cnpq.br

Research partially supported by CNPq (No. 477577/2004-0) and CAPES (Master's fellowship).

Received December 15, 2006 Accepted July 4, 2007

\begin{abstract}
The objective of the present study was to evaluate breathing pattern, thoracoabdominal motion and muscular activity during three breathing exercises: diaphragmatic breathing (DB), flow-oriented (Triflo II) incentive spirometry and volume-oriented (Voldyne) incentive spirometry. Seventeen healthy subjects (12 females, 5 males) aged $23 \pm$ 5 years (mean \pm SD) were studied. Calibrated respiratory inductive plethysmography was used to measure the following variables during rest (baseline) and breathing exercises: tidal volume (Vt), respiratory frequency $(f)$, rib cage contribution to $\mathrm{Vt}(\mathrm{RC} / \mathrm{Vt})$, inspiratory duty cycle (Ti/Ttot), and phase angle (PhAng). Sternocleidomastoid muscle activity was assessed by surface electromyography. Statistical analysis was performed by ANOVA and Tukey or Friedman and Wilcoxon tests, with the level of significance set at $\mathrm{P}<0.05$. Comparisons between baseline and breathing exercise periods showed a significant increase of $\mathrm{Vt}$ and $\mathrm{PhAng}$ during all exercises, a significant decrease of $f$ during DB and Voldyne, a significant increase of Ti/Ttot during Voldyne, and no significant difference in $\mathrm{RC} / \mathrm{Vt}$. Comparisons among exercises revealed higher $f$ and sternocleidomastoid activity during Triflo II $(\mathrm{P}<0.05)$ with respect to $\mathrm{DB}$ and Voldyne, without a significant difference in $\mathrm{Vt}, \mathrm{Ti} / \mathrm{Tt}$ tot, PhAng, or RC/Vt. Exercises changed the breathing pattern and increased PhAng, a variable of thoracoabdominal asynchrony, compared to baseline. The only difference between DB and Voldyne was a significant increase of Ti/Ttot compared to baseline. Triflo II was associated with higher $f$ values and electromyographic activity of the sternocleidomastoid. In conclusion, DB and Voldyne showed similar results while Triflo II showed disadvantages compared to the other breathing exercises.
\end{abstract}

\section{Introduction}

Deep and slow inspiration is considered to be a therapeutic breathing exercise. Deep inspirations imitating a yawn or a sigh mechanism promote an increase in transpulmo-
Key words

- Diaphragmatic breathing

- Incentive spirometry

- Chest physiotherapy

- Breathing pattern

- Electromyography

- Respiratory inductive plethysmography 
tions, especially atelectasis $(1,2)$.

This maneuver can be done with or without auxiliary instruments. When carried out without instruments, it is commonly called diaphragmatic breathing (DB) (3). Although DB is present in many chest physiotherapy procedures, little attention has been paid to the analysis of the mechanisms responsible for the specific effects of this type of treatment (4).

In contrast, incentive spirometry (IS) involves the use of incentive spirometer devices (5). IS has been used since the 1970's when Bartlett et al. (2) developed and described the first incentive spirometer with the objective of ensuring that the patient would perform slow and sustained deep inspirations, encouraged by visual feedback. Since then, volume- or flow-oriented incentive spirometers have become more popular, with different brands being available (6-8).

Deep breathing exercises and IS have been compared in two controlled and randomized clinical trials $(9,10)$. Jenkins et al. (10) observed that the addition of deep breathing exercises or IS to conventional chest physiotherapy (early mobilization, huffing and coughing) did not alter pulmonary function or the prevention of postoperative pulmonary complications after coronary artery bypass surgery. Celli et al. (9) conducted a study in which three kinds of treatment (intermittent positive pressure breathing, IS and deep breathing exercises) showed equivalent efficacy in the prevention of postoperative pulmonary complications after abdominal surgery. Patients treated with IS presented a significantly shorter hospitalization period. Taking into consideration the results of this study and given the economic implications of each type of treatment, Celli et al. (9) pointed out the need for more studies comparing IS and deep breathing exercises.

Recently, we conducted two studies related to the evaluation of breathing pattern and thoracoabdominal motion during IS $(11,12)$. Initially, four different incentive spirometers were analyzed, two volume-oriented and two flow-oriented. The results showed that there was a significantly higher abdominal motion during the use of volumeoriented incentive spirometers compared to flow-oriented devices (12). Later, the influence of body position (inclinations of $30^{\circ}$ and $45^{\circ}$ ) was analyzed during the use of the two spirometers (flow-oriented and volumeoriented). The abdominal motion was significantly higher at $30^{\circ} \mathrm{C}$ during the use of the volume-oriented device (11). A higher abdominal motion can be considered to be an important result since IS is indicated for the prevention of atelectasis, which mainly affects the pulmonary bases (8).

In addition to breathing pattern and thoracoabdominal motion, muscular activity is another important parameter that can contribute to the evaluation of the respiratory system. Surface electromyography is a noninvasive method for the evaluation of muscular activity and has been used in research for the analysis of surface muscles, including neck muscles that participate in breathing (13-15). Costa et al. (13) studied the participation of the sternocleidomastoid muscle (SCM) during different inspiratory maneuvers in healthy subjects and observed that this muscle was active during high levels of ventilation. To the best of our knowledge, no studies comparing muscular activity during DB and IS have been conducted.

The main objective of the present study was to analyze breathing pattern, thoracoabdominal motion and SCM muscular activity during DB and IS using a volume-oriented device (Voldyne) and a flow-oriented device (Triflo II).

\section{Subjects and Methods}

\section{Subjects}

Twenty-six healthy volunteers were selected from a sample of university students and workers. The inclusion criteria were: 
being 18 to 44 years old, having a normal body mass index, being a non-smoker, not knowing the DB and the IS techniques, and reporting the absence of respiratory diseases. The exclusion criteria were: presenting alteration in respiratory function detected by functional analysis of lung volume and capacity and/or inability to understand or perform the procedure. The Ethics Research Committee of the Universidade Federal de Minas Gerais approved the protocol used, and all subjects gave informed written consent.

\section{Signals and measurements}

Initial interview and functional analysis of lung volume and capacity. Evaluation was carried out using questions about physical activities, exposure to a risky environment for respiratory illnesses, and previous and/or current diseases, based on a guideline for pulmonary function tests (16). Functional analysis of lung volume and capacity was carried out using a portable spirometer (Vitalograph $2120^{\circledR}$, Vitalograph, Buckingham, England) to ensure a normal lung function. Criteria of acceptance and reproducibility were observed (16). The values of the spirometric variables were compared to predicted values according to Knudson et al. (17).

Breathing pattern and thoracoabdominal motion. Inductive respiratory plethysmography (Respitrace ${ }^{\circledR}$ 204, Nims, Miami, FL, USA) was used to assess breathing pattern and thoracoabdominal motion. The accuracy of plethysmography in the evaluation of breathing pattern has been determined at rest and during physical activity in both adults and children (18). Tidal volume $(\mathrm{Vt})$ measurements are satisfactory as long as the body position remained constant after the calibration procedure (18). The system consisted of two bands (Teflon ${ }^{\circledR}$-coated inductance) measuring changes in cross-sectional area of the rib cage $(\mathrm{RC})$ and abdomen
(AB). Bands of appropriate size were placed around the $\mathrm{RC}$ and $\mathrm{AB}$; the upper edge of the $\mathrm{RC}$ band was placed at the level of the axilla and the abdominal band at the level of the umbilicus. Signals were calibrated using qualitative diagnostic calibration (19). A detailed description of the calibration procedure has been recently published (12).

The following variables were measured via a digital acquisition system on a breathby-breath basis (RespiEvents, Nims): Vt, respiratory frequency $(f)$, minute ventilation (VE), inspiratory time (Ti), inspiratory duty cycle (Ti/Ttot), mean inspiratory flow (Vt/ $\mathrm{Ti})$, rib cage motion contribution to $\mathrm{Vt}(\mathrm{RC} /$ $\mathrm{Vt}$ ), and phase angle (PhAng). The contribution of abdominal motion to $\mathrm{Vt}(\mathrm{AB} / \mathrm{Vt})$ was calculated as $\mathrm{AB} / \mathrm{Vt}=100-\mathrm{RC} / \mathrm{Vt}$. PhAng is a variable that reflects thoracoabdominal asynchrony.

Electromyographic activity of the sternocleidomastoid muscle. Surface electromyography was used to record electromyographic muscular activity of the right SCM muscle during maximal inspiratory pressure (MIP) measurements and during the breathing exercises.

Data acquisition was carried out using an eight-channel biological signal acquisition system (EMG System Ltda., São José dos Campos, SP, Brazil) consisting of a signal conditioner with a gain of 1000 , a high-pass filter of $20 \mathrm{~Hz}$, and a low-pass filter of 500 $\mathrm{Hz}$, a specific software for data acquisition and analysis (Aqdados, São José dos Campos, SP, Brazil) and a 12-bit analogue-todigital converter, with a sample frequency of $2000 \mathrm{~Hz}$. Aqdados is a program which allows the storage of data in files and mathematic process to calculate the root mean square. To prevent electromagnetic interference and other noises, the lights and cell phones were switched off. Subjects were instructed to remove any metal objects that were near the active electrodes or the reference electrode, and their skin was prepared prior to electrode positioning. 
For data collection, a pair of bipolar active surface electrodes (silver/silver chloride, round-shaped, measuring $1 \mathrm{~cm}^{2}$ and equipped with an internal amplifier) were used. After cleaning the skin with $70 \%$ isopropyl alcohol the electrodes were positioned at the midpoint of the belly of the right SCM. Initial positioning and orientation of the electrodes were based on palpation of the muscle belly during manually resisted neck flexion contractions (20). Next, the distance between the mastoid process and the sternoclavicular joint was measured in order to locate the midpoint of the sternal portion of the muscle belly. The electrodes were positioned in this area separated by a distance of approximately $2.5 \mathrm{~cm}$. For protection of the volunteers and to avoid electromagnetic interference during data collection, a reference electrode was positioned on the ulnar styloid process of the right forearm. Subjects were required to perform a small neck flexion isometric contraction to ensure that the electrodes were in the appropriate position (20).

After confirming the position of the electrodes, MIP measurements were made in order to normalize the electromyographic data. Measurements were made with a manovacuometer (GeRar ${ }^{\circledR}$, São Paulo, SP, Brazil) using a specific protocol (21). For an adequate comparison of the electromyographic activity of the right SCM during DB, Triflo II and Voldyne, data collected during MIP measurements were used to calculate the percentage of muscle activation during each respiratory exercise related to the electromyographic activity recorded during MIP measurements.

\section{Intervention}

Two modalities of respiratory exercises based on deep and slow inspirations were used: DB and IS. During DB, the researcher placed one hand slightly below the lower ribs in the abdominal region of the subject and the subject was instructed to perform inspirations up to the maximum level of volume avoiding rib cage displacement (3); this recommendation was also valid for exercises using incentive spirometers. IS was executed using two different devices: Triflo II (Hudson RCI, Temecula, CA, USA) and Voldyne (Hudson RCI). During exercise with Triflo II, subjects were instructed to execute deep inspirations raising the first two balls of the device, which corresponded to a mean $\mathrm{Vt} / \mathrm{Ti}$ of $900 \mathrm{~mL} / \mathrm{s}$. This criterion was based on manufacturer recommendations. During exercise with Voldyne, subjects were instructed to perform maximum inspirations regardless of the level observed in the cylinder.

\section{Procedure}

After an initial interview and functional analysis of lung volume and capacity, MIP was measured. The subjects comfortably lay in bed in the supine position with $30^{\circ}$ of inclination $(11,22)$ and were instructed about how to perform the breathing exercises. Subjects repeated each exercise about three times and had the chance to express their doubts before the beginning of data collection.

Breathing pattern and thoracoabdominal motion, as well as electromyographic activity of the right SCM muscle were recorded at rest (baseline) and during the respiratory exercises. A 5-min baseline period was first recorded, followed by recording of the first breathing exercise. Eight to 10 respiratory cycles were required during each exercise (6). After each period of exercise, a baseline period was recorded. A total of three baseline periods and three exercise periods were recorded. The order of execution of the three exercises was randomized by a specific computer program (MatLab ${ }^{\circledR}$, Natick, MA, USA). Transcutaneous oxygen saturation $\left(\mathrm{SaO}_{2}\right)$ and heart rate were measured by pulse oximetry (Datex-Ohmeda Inc., Louisville, CO, USA).

\section{Statistical analysis}

Data are reported as means $\pm \mathrm{SD}$. Distri- 
bution analysis was performed using the Kolmogorov-Smirnov test. When distribution was normal, comparisons between baseline and breathing exercises or between exercises were performed with ANOVA for repeated measures followed by the post hoc Tukey test; when distribution was not normal, the Friedman and Wilcoxon tests were used for these comparisons, respectively. The Student $t$-test for paired samples was used to compare pre- and post-trial $\mathrm{SaO}_{2}$ and pulse rate when distribution was considered to be normal; for data not normally distributed, the Wilcoxon test was used. The level of significance $(\alpha)$ was set at 0.05 (twotailed) for all tests. Bonferroni correction was used, modifying the level of significance to 0.017 or 0.008 according to the number of contrasts performed (23). Data were analyzed with the Statistical Package for the Social Sciences (SPSS 10.0, Chicago, IL, USA).

\section{Results}

Nine of the 26 volunteers were excluded $(6$ for presenting alteration in respiratory function and 3 for being unable to complete the procedures). Thus, 17 subjects ( 5 men and 12 women) were studied, with the following characteristics (mean $\pm \mathrm{SD}$ ): age, $22.71 \pm 4.74$ years (range 19 to 38 years); weight, $59.82 \pm$ $9.90 \mathrm{~kg}$; height, $1.67 \pm 0.10 \mathrm{~m}$; body mass index, $21.33 \pm 1.65 \mathrm{~kg} / \mathrm{m}^{2}$. The mean values of the spirometric variables, shown as a percentage of the values predicted by Knudson et al. (17), were: forced vital capacity (FVC) $=92.54$ $\pm 6.08 \%$, forced expiratory volume in $1 \mathrm{~s}$ $\left(\mathrm{FEV}_{1}\right)=96.07 \pm 5.12 \%, \mathrm{FEV}_{1} / \mathrm{FVC}=104.32$ $\pm 7.31 \%$, peak expiratory flow $(\mathrm{PEF})=99.21$ $\pm 11.14 \%$, and forced expiratory flow at 25 $75 \%$ of maximum lung volume $=96.43 \pm$ $17.23 \%$, characterizing subjects with normal respiratory function (16). $\mathrm{SaO}_{2}$ and heart rate were within normal values, ranging from 96.24 \pm 1.39 to $98.00 \pm 1.00 \%$ and from $71.13 \pm 9.23$ to $80.65 \pm 9.80 \mathrm{bpm}$, respectively (24).
Among the 17 subjects, 4 repeated one of the exercise periods ( 1 with DB, 2 with Triflo II, and 1 with Voldyne) because of artifacts on the plethysmographic or electromyographic tracing. Twelve of the 17 subjects practiced a regular physical activity, and 5 were sedentary at the time of data collection.

\section{Breathing pattern and thoracoabdominal motion}

Data regarding breathing pattern and thoracoabdominal motion were obtained during the three baseline periods and the three exercise periods for all subjects except one, whose Voldyne data could not be analyzed due to excessive artifacts. A minimum of 1 min of steady state during the baseline periods and a minimum of five breath cycles during the exercises were analyzed. A total of 1397 breath cycles were analyzed: 957 during the baseline periods (average of 17.72 \pm 3.92 breathing cycles per subject), 141 cycles during DB $(7.83 \pm 2.01), 160$ during the use of Triflo II $(8.89 \pm 2.47)$, and 139 during the use of Voldyne $(8.18 \pm 2.04)$. There were no significant differences among the three baseline periods considering the variables $\mathrm{Vt}, f, \mathrm{RC} / \mathrm{Vt}$, and $\mathrm{PhAng}(\mathrm{P}=$ $0.958,0.945,0.990$, and 0.398 , respective1y). Thus, only the first baseline period was considered in the subsequent comparisons.

The results obtained at baseline periods and during exercise (DB, Triflo II and Voldyne) Triflo II and are shown in Table 1. Significant increases in Vt, VE, Ti, Vt/Ti, and PhAng occurred during the three types of exercise. There was a significant increase in Ti/Ttot during the use of Voldyne, and no significant difference during DB and Triflo II. The $f$ value decreased significantly during DB and Voldyne compared to baseline, whereas no significant change was observed between baseline and Triflo II. No significant difference was observed between baseline and exercise in $\mathrm{RC} /$ $\mathrm{Vt}$ and $\mathrm{AB} / \mathrm{Vt}$, in Ti/Ttot during DB and Triflo 
II, or in $f$ during Triflo II.

Comparisons between the three types of exercise showed no significant differences in $\mathrm{Vt}, \mathrm{Ti} / \mathrm{Tt}$ tot, $\mathrm{RC} / \mathrm{Vt}, \mathrm{AB} / \mathrm{Vt}$, or PhAng. A higher $f$ value was observed and, consequently, a higher VE during Triflo II compared to DB and Voldyne. Ti was significantly lower and associated with a significantly higher Vt/Ti during Triflo II compared to DB and Voldyne.

\section{Electromyographic activity of the sternocleidomastoid muscle}

The electromyographic activity of the right SCM was determined in all 17 subjects

Figure 1. Sternocleidomastoid (SCM) activity during diaphragmatic breathing (DB), flow-oriented incentive spirometry (Triflo II) and volume-oriented incentive spirometry (Voldyne) for the 17 subjects. Data are reported as means $\pm \mathrm{SD}$, as percentage of root mean square (RMS) values recorded during maximal inspiratory pressure measurements. Statistical comparisons were performed with the Friedman and Wilcoxon tests. The level of significance $(\alpha)$ was set at 0.05 and adjusted for 0.017 with Bonferroni correction $(0.05$ / $3=0.017) .{ }^{*} \mathrm{P}<0.05$ for comparisons between breathing exercises. during measurements of MIP and breathing exercises. A minimum of $1 \mathrm{~s}$ of recording during MIP measurements and $30 \mathrm{~s}$ of recording during each exercise were analyzed. Figure 1 presents percent electromyographic activity of the SCM during breathing exercises in relation to MIP measurements. During the use of Triflo II, there was a significantly higher SCM activity compared to both Voldyne and DB, without a significant difference between DB and Voldyne.

\section{Discussion}

The main results of this study were: 1) comparisons between baseline and exercise periods showed a significant increase in $\mathrm{Vt}$ during all exercises and a significant decrease in $f$ during the use of DB and Voldyne; there was a significant increase in $\mathrm{Ti} / \mathrm{Ttot}$ only during the use of Voldyne. 2) Comparisons between exercises showed no significant differences between DB and Voldyne in any variable. During exercise with Triflo II, $f, \mathrm{VE}$, and $\mathrm{Vt} / \mathrm{Ti}$ values were significantly higher, and $\mathrm{Ti}$ values were significantly lower. 3) Regarding thoracoabdominal mo-

Table 1. Respiratory variables at rest (baseline), and during diaphragmatic breathing, flow-oriented incentive spirometry (Triflo II) and volume-oriented incentive spirometry (Voldyne) for 17 subjects.

\begin{tabular}{lcccc}
\hline Variables & Baseline & Diaphragmatic breathing & Triflo II & Voldyne \\
\hline $\mathrm{Vt}(\mathrm{mL})$ & $307.75 \pm 35.65$ & $1475.01 \pm 666.83^{*}$ & $1263.35 \pm 433.05^{*}$ & $1738.75 \pm 780.41^{*}$ \\
$f(\mathrm{bpm})$ & $16.64 \pm 4.09$ & $7.88 \pm 2.54^{*}$ & $14.15 \pm 5.15^{+}$ & $8.13 \pm 2.45^{*}$ \\
$\mathrm{VE}(\mathrm{L} / \mathrm{min})$ & $4.85 \pm 2.07$ & $11.30 \pm 5.80^{*}$ & $18.51 \pm 7.16^{*+}$ & $13.42 \pm 5.90^{*}$ \\
$\mathrm{Ti}(\mathrm{s})$ & $1.46 \pm 0.29$ & $3.69 \pm 1.38^{*}$ & $1.77 \pm 0.59^{*+}$ & $4.02 \pm 2.04^{*}$ \\
$\mathrm{Ti} / \mathrm{Ttot}$ & $0.38 \pm 0.03$ & $0.44 \pm 0.07$ & $0.41 \pm 0.06$ & $0.47 \pm 0.10^{*}$ \\
$\mathrm{Vt} / \mathrm{Ti}(\mathrm{mL} / \mathrm{s})$ & $211.66 \pm 88.48$ & $439.62 \pm 228.83^{*}$ & $761.27 \pm 268.95^{*+}$ & $520.34 \pm 282.14^{*}$ \\
$\mathrm{RC} / \mathrm{Vt}(\%)$ & $36.46 \pm 14.36$ & $41.98 \pm 20.59$ & $49.30 \pm 23.93$ & $54.31 \pm 20.24$ \\
$\mathrm{AB} / \mathrm{Vt}(\%)$ & $63.54 \pm 14.36$ & $58.02 \pm 20.59$ & $50.70 \pm 23.93$ & $45.69 \pm 20.24$ \\
$\mathrm{PhAng}($ degree $)$ & $11.42 \pm 6.28$ & $30.32 \pm 13.20^{*}$ & $34.81 \pm 29.69^{*}$ & $30.94 \pm 16.77^{*}$
\end{tabular}

Data are reported as means $\pm \mathrm{SD}$. $\mathrm{Vt}=$ tidal volume, $f=$ respiratory frequency, $\mathrm{VE}=$ minute ventilation, $\mathrm{Ti}=$ inspiratory time, $\mathrm{Ti} / \mathrm{T}$ tot $=$ inspiratory duty cycle, $\mathrm{Vt} / \mathrm{Ti}=$ mean inspiratory flow, $\mathrm{RC} / \mathrm{Vt}=$ rib cage motion contribution to $\mathrm{Vt}, \mathrm{AB} / \mathrm{Vt}=$ abdominal motion contribution to $\mathrm{Vt}, \mathrm{PhAng}=$ phase angle.

Statistical comparisons were performed with ANOVA for repeated measures and the post hoc Tukey test (data normally distributed: $\mathrm{Ti} / \mathrm{Ttot}, \mathrm{RC} / \mathrm{Vt}$, and $\mathrm{AB} / \mathrm{Vt}$ ), or the Friedman and Wilcoxon tests (data not normally distributed: $\mathrm{Vt}, f, \mathrm{VE}, \mathrm{Ti}, \mathrm{Vt} / \mathrm{Ti}$, and $\mathrm{PhAng}$ ). The level of significance $(\alpha)$ was set at 0.05 and adjusted for 0.008 with Bonferroni correction $(0.05 / 6=0.008)$. ${ }^{*} P<0.05$ for comparisons between baseline and breathing exercises; ${ }^{+} \mathrm{P}<0.05$ for comparisons between breathing exercises. 
tion, comparisons between baseline and exercises or between exercises showed no significant changes in $\mathrm{RC} / \mathrm{Vt}$ or $\mathrm{AB} / \mathrm{Vt}$. During all exercises, there was an increase in PhAng compared to baseline, reflecting an increase in thoracoabdominal asynchrony. 4) A higher electromyographic activity of the SCM occurred during exercise with Triflo II compared to the other exercises.

A question may be raised about the fact that only the first baseline period was considered in the comparisons between baseline and exercises. This choice was made because there were no significant differences between the three baselines. The periods of baseline between exercises were necessary to prevent carryover effects. A period of 5 min was sufficient for the recovery of basal values, as also observed in previous studies $(11,12)$. In order to eliminate cumulative effects, exercises were randomized.

Regarding the physiology of deep and slow inspiration, the basis of DB and IS, an increase in $\mathrm{Vt}$ is expected, associated with a decrease in $f(1,6)$ and an increase in Ti/Ttot (25), which can contribute to a laminar inspiratory flow, resulting in a more uniform distribution of air through the pulmonary parenchyma. The variables analyzed showed the same results during DB and Voldyne, except for Ti/Ttot, which only increased significantly during exercise with Voldyne compared to baseline. Thus, the changes expected as a consequence of deep and slow inspirations occurred in a significant and concomitant way compared to baseline only during Voldyne. Comparisons between deep breathing exercise and IS were performed in previous studies $(9,10)$ in terms of different aspects of pulmonary function, but not in terms of breathing pattern variables as was done in the present study.

Minute ventilation was significantly higher during Triflo II and this can be associated with a decreased risk of hypoxemia (26). However, this higher VE seems to be a consequence of high values of $f$, since $\mathrm{Vt}$ was similar between exercises, an important objective of deep breathing exercises (25). Vt/Ti was significantly higher during exercise with Triflo II. It should be pointed out that during exercise with Triflo II, Vt/Ti was limited to the level corresponding to the elevation of the first two balls. However, $f$ was not pre-determined for any exercise and was also significantly higher during exercise with Triflo II in relation to the other exercises.

Another result that can be considered to be a disadvantage of Triflo II was a higher electromyographic activity of the SCM during the use of this device compared to the other exercises. Previous studies have shown a higher electromyographic activity of the SCM associated with an increased load in the respiratory system. Costa et al. (13) assessed the participation of the SCM during deep inspiration in healthy adults and observed a higher electromyographic activity of the SCM when inspiratory movements were performed in a fast and abrupt way compared to slow inspirations. De Andrade et al. (27) reported an increase of $7 \%$ in the electromyographic activity of the SCM during muscular training with Threshold ${ }^{\circledR}$ (Respironics, Cedar Grove, NJ, USA).

High $f$ levels and electromyographic activity of respiratory muscles can be related to increased breathing work $(25,28)$. In previous studies, a higher imposed breathing work was observed during flow-oriented IS compared to volume-oriented IS $(28,29)$. Mang and Obermayer (29) assessed six different incentive spirometers using a lung model and observed a higher imposed breathing work during exercise with Triflo II. These investigators reported that the increase in breathing work was proportional to the increase in inspiratory flow. Weindler and Kiefer (28) studied the impact of imposed breathing work during IS in patients with high and moderate risk of postoperative pulmonary complications and observed that, in patients with a moderate risk, the floworiented device imposed an additional work two times higher than that imposed by the 
volume-oriented device. During the postoperative period of abdominal surgery, when IS is classically indicated, breathing work can increase significantly as a consequence of atelectasis, weakness of inspiratory muscles and excessive airway mucus secretion (30). On this basis, we suggest that a device associated with a lower additional imposed work should be chosen.

With respect to thoracoabdominal motion, there were no significant differences in $\mathrm{RC} / \mathrm{Vt}$ or $\mathrm{AB} / \mathrm{Vt}$ between baseline and exercise or between exercises. These results are different from those reported in previous studies, probably because of differences between healthy subjects and patients. Chuter et al. (31) observed an increase in $\mathrm{RC} / \mathrm{Vt}$ during IS compared to baseline after cholecystectomy. We may speculate that this result was consequent to an increased abdominal pressure related to surgery (32).

Sharp et al. (33), in a study with healthy subjects, observed that 61 and $50 \%$ of subjects, respectively, showed an increasing participation of rib cage and abdomen with increasing tidal volume during deep inspirations performed in the supine position. In the upright position, nearly all the volume change was due to rib cage displacement, with much less abdominal participation compared to the supine position. In this case, results different from ours may be related to different methods used to instruct subjects and different devices used to assess thoracoabdominal motion, since the cited investigators used magnetometer, whereas we used respiratory inductive plethysmography.

Parreira et al. (12), in 2005, observed an increase in the contribution of abdominal motion to Vt during volume-oriented IS compared to flow-oriented IS, with subjects in the supine position with $45^{\circ}$ of inclination and with parameter limitation during IS. In the present study, subjects were positioned at $30^{\circ}$ of inclination and instructed to perform deep inspirations without limitations. Thus, different study designs probably contributed to differences in the results.

Asynchrony between the thoracic and abdominal compartments was assessed by PhAng $(34,35)$. When rib cage and abdomen move in perfect synchrony, $\mathrm{PhAng}$ is $0^{\circ}$, and with increasing thoracoabdominal asynchrony its value approaches $180^{\circ}$ (34). We did not find any literature reports about $\mathrm{PhAng}$ values for healthy adults during breathing exercises. The baseline PhAng values observed here during baseline were similar to those observed in previous studies with healthy subjects during breathing at rest (35-37). When compared to baseline, there was a significant increase in PhAng during all exercises, without differences between them. A priori, these results can be related to an increased respiratory load imposed on the respiratory system (37).

Our results suggest that the execution of the three breathing exercises caused changes in the volume and time components of the breathing pattern and increased asynchrony when compared to baseline. Diaphragmatic breathing and the volume-oriented incentive spirometer Voldyne showed similar performance. Considering breathing pattern variables, SCM electromyographic activity and the physiology of techniques based on deep and slow inspirations, our results suggest that the flow-oriented incentive spirometer Triflo II presented important disadvantages compared to the other exercises studied.

\section{Acknowledgments}

The authors thank Miss Dora Tomich for her careful revision of the manuscript. 


\section{References}

1. Bakow ED. Sustained maximal inspiration - a rationale for its use. Respir Care 1977; 22: 379-382.

2. Bartlett RH, Gazzaniga AB, Geraghty TR. Respiratory maneuvers to prevent postoperative pulmonary complications. A critical review. JAMA 1973; 224: 1017-1021.

3. Gosselink HAAM. Breathing exercises in patients with chronic obstructive pulmonary disease - An experimental study on the efficiency and coordination of breathing. Amsterdam: Vrije Universiteit te Amsterdam; 1991.

4. Gosselink R, Schrever K, Cops P, Witvrouwen H, De Leyn P, Troosters $T$, et al. Incentive spirometry does not enhance recovery after thoracic surgery. Crit Care Med 2000; 28: 679-683.

5. Grant-Paterson L, Moodie NB. Incentive spirometry: an adjunct to chest physiotherapy. Physiother Can 1985; 37: 388-393.

6. AARC (American Association for Respiratory Care) clinical practice guideline. Incentive spirometry. Respir Care 1991; 36: 1402-1405.

7. Douce FH. Incentive spirometry and other aids to lung inflation. In: Barnes G (Editor), Core text book. 1st edn. New York: McGraw Hill; 1994. p 231-241.

8. Wojciechowski WV. Incentive spirometers, secretion evacuation devices, and inspiratory muscle training devices. In: Barnes G (Editor), Core text book. 1st edn. New York: McGraw Hill; 1994. p 499522.

9. Celli BR, Rodriguez KS, Snider GL. A controlled trial of intermittent positive pressure breathing, incentive spirometry, and deep breathing exercises in preventing pulmonary complications after abdominal surgery. Am Rev Respir Dis 1984; 130: 12-15.

10. Jenkins SC, Soutar SA, Loukota JM, Johnson LC, Moxham J. Physiotherapy after coronary artery surgery: are breathing exercises necessary? Thorax 1989; 44: 634-639.

11. Parreira VF, Coelho EM, Tomich GM, Alvim AMA, Sampaio RF, Britto RR. Avaliação do volume corrente e da configuração toracoabdominal durante o uso de espirômetros de incentivo a volume e a fluxo, em sujeitos saudáveis: influência da posição corporal. Rev Bras Fisioter 2004; 8: 45-51.

12. Parreira VF, Tomich GM, Britto RR, Sampaio RF. Assessment of tidal volume and thoracoabdominal motion using volume and floworiented incentive spirometers in healthy subjects. Braz J Med Biol Res 2005; 38: 1105-1112.

13. Costa D, Vitti M, de Oliveira TD, Costa RP. Participation of the sternocleidomastoid muscle on deep inspiration in man. An electromyographic study. Electromyogr Clin Neurophysiol 1994; 34: 315320.

14. Maarsingh EJ, van Eykern LA, Sprikkelman AB, Hoekstra MO, van Aalderen WM. Respiratory muscle activity measured with a noninvasive EMG technique: technical aspects and reproducibility. J Appl Physiol 2000; 88: 1955-1961.

15. Winter DA, Fuglevand AJ, Archer SE. Crosstalk in surface electromyography: theoretical and practical estimates. J Electromyogr Kinesiol 1994; 4: 15-26.

16. Pereira CAC. Espirometria. J Bras Pneumol 2002; 28 (Suppl 3): S1S82.

17. Knudson RJ, Lebowitz MD, Holberg CJ, Burrows B. Changes in the normal maximal expiratory flow-volume curve with growth and aging. Am Rev Respir Dis 1983; 127: 725-734.

18. Chadha TS, Watson H, Birch S, Jenouri GA, Schneider AW, Cohn MA, et al. Validation of respiratory inductive plethysmography using different calibration procedures. Am Rev Respir Dis 1982; 125: 644649.
19. Sackner MA, Watson H, Belsito AS, Feinerman D, Suarez M, Gonzalez $\mathrm{G}$, et al. Calibration of respiratory inductive plethysmograph during natural breathing. J Appl Physiol 1989; 66: 410-420.

20. Falla D, Dall'Alba P, Rainoldi A, Merletti R, Jull G. Repeatability of surface EMG variables in the sternocleidomastoid and anterior scalene muscles. Eur J Appl Physiol 2002; 87: 542-549.

21. Souza RB. Pressões respiratórias estáticas máximas. J Bras Pneumol 2002; 28 (Suppl 3): S155-S165.

22. Melendez JA, Alagesan R, Reinsel R, Weissman C, Burt M. Postthoracotomy respiratory muscle mechanics during incentive spirometry using respiratory inductance plethysmography. Chest 1992; 101: 432-436.

23. Munro BH. Repeated measures analysis of variance. In: Munro BH (Editor), Statistical methods for health and care research. 4th edn. Philadelphia: Lippincott Williams \& Wilkins; 2000. p 201-221.

24. Webber BA, Pryor JA. Physiotherapy for respiratory and cardiac problems. New York: Churchill Livingstone; 1998.

25. Grassi C, Brambilla C, Fishman AP. Pulmonary diseases. London: McGraw-Hill International; 1999.

26. West JB. Mecânica da respiração. Fisiologia respiratória moderna. São Paulo: Manole Ltda.; 1996.

27. De Andrade AD, Silva TN, Vasconcelos H, Marcelino M, RodriguesMachado MG, Galindo VC, et al. Inspiratory muscular activation during threshold therapy in elderly healthy and patients with COPD. J Electromyogr Kinesiol 2005; 15: 631-639.

28. Weindler J, Kiefer RT. The efficacy of postoperative incentive spirometry is influenced by the device-specific imposed work of breathing. Chest 2001; 119: 1858-1864.

29. Mang $\mathrm{H}$, Obermayer $\mathrm{A}$. Imposed work of breathing during sustained maximal inspiration: comparison of six different incentive spirometers. Respir Care 1989; 34: 1122-1128.

30. Marini JJ. Postoperative atelectasis: pathophysiology, clinical importance, and principles of management. Respir Care 1984; 29 : 516-522.

31. Chuter TAM, Weisman C, Starker P, Gump FE. Effect of incentive spirometry on diaphragmatic function after surgery. Surgery 1989; 105: 488-493.

32. Simonneau G, Vivien A, Sartene R, Kunstlinger F, Samii K, Noviant $\mathrm{Y}$, et al. Diaphragm dysfunction induced by upper abdominal surgery. Role of postoperative pain. Am Rev Respir Dis 1983; 128 : 899-903.

33. Sharp JT, Goldberg NB, Druz WS, Danon J. Relative contributions of rib cage and abdomen to breathing in normal subjects. J Appl Physiol 1975; 39: 608-618.

34. Mayer OH, Clayton RG Sr, Jawad AF, McDonough JM, Allen JL. Respiratory inductance plethysmography in healthy 3- to 5-year-old children. Chest 2003; 124: 1812-1819.

35. Sackner MA, Gonzalez H, Rodriguez M, Belsito A, Sackner DR, Grenvik S. Assessment of asynchronous and paradoxic motion between rib cage and abdomen in normal subjects and in patients with chronic obstructive pulmonary disease. Am Rev Respir Dis 1984; 130: 588-593.

36. Bloch KE, Li Y, Zhang J, Bingisser R, Kaplan V, Weder W, et al. Effect of surgical lung volume reduction on breathing patterns in severe pulmonary emphysema. Am J Respir Crit Care Med 1997; 156: 553-560.

37. Tobin MJ, Perez W, Guenther SM, Lodato RF, Dantzker DR. Does rib cage-abdominal paradox signify respiratory muscle fatigue? $J$ Appl Physiol 1987; 63: 851-860. 